\title{
Some Contributions to Knowledge of Stress Response in Innovative Species with Particular Focus on the Use of the Anaesthetics
}

\author{
Giulia Maricchiolo* and Lucrezia Genovese
}

National Research Council, Institute for Coastal Marine Environment, Messina, Italy

\begin{abstract}
This study investigated some aspects of stress research, including, also, the effects of chemical anaesthesia, in two important species for diversification in aquaculture, blackspot seabream, Pagellus bogaraveo and greater amberjack, Seriola dumerilii. The first part of the research (trial 1 and 2) was designed to determine the efficacy of clove oil as an anaesthetic alternative to MS-222. In trial 1, the minimum concentration of anaesthetic producing the total loss of muscular tone within $3 \mathrm{~min}$, and recovery within $10 \mathrm{~min}$, was determined. The obtained results showed that MS-222 and clove oil were effective as anaesthetics for juveniles of blackspot sea-bream and greater amberjack at concentrations of 40 and $100 \mathrm{mg} \mathrm{L}^{-1}$, respectively. The aim of trial 2 was to assess the side-effects of both anaesthetics on greater amberjack juveniles by monitoring serum cortisol and glucose levels, and haematocrit values. No significant differences between anaesthetics were found for most of the measured physiological variables. The second part of research (trial 3) was designed to establish the ability of anaesthesia to mitigate stress responses blocking activation of the HPI axis associated to handling stress. In this trial, the stress responses to handling of adult blackspot sea-bream anaesthetised with either anaesthetics were compared to those of unanaesthetised fish used as controls. Serum cortisol and glucose concentrations were used as stress indicators. Both anaesthetics were unable to block activation of the HPI axis that occurs as a consequence of handling stress in blackspot sea-bream, although anaesthesia with both anaesthetics proved to be effective in reducing the duration of stress response.
\end{abstract}

Keywords: Pagellus bogaraveo, Seriola dumerilii, stress response, anaesthesia, tricaine methanesulfonate, clove oil, physiological parameters.

\section{INTRODUCTION}

\subsection{Fish Welfare and Stress in Aquaculture}

Over the last decade, finfish aquaculture production has experienced a worldwide expansion and is projected to become an increasingly significant source of animal proteins; it is estimated that, by 2015 , about $39 \%$ of world fish production will come from aquaculture [1].

The importance of animal welfare is now recognised in all animal productions including those from aquaculture. Fish welfare is an important issue for aquaculture industry for production efficiency, quantity and product quality as well as for consumer perception and marketing [2-4].

However, while there is a well established literature on welfare of terrestrial farm animals, for fish under intensive aquaculture conditions there is a paucity of scientific information on which to base future guidelines and potential legislation where necessary. There are many aquaculture practices that may compromise fish welfare (see [5] for a review).

Fish react to stress with a primary neuroendocrine response, represented by a rapid release of catecholamines (adrenaline and noradrenaline) from the chromaffin tissue (homologous to the mammalian adrenal medulla) and by the

*Address correspondence to this author at the National Research Council, Institute for Coastal Marine Environment (IAMC), Spianata S. Raineri, $86-$ 98122 Messina, Italy; Tel: (+39) 90669003; Fax: (+39) 90669007;

E-mail: giulia.maricchiolo@iamc.cnr.it activation of hypothalamic-pituitary-interrenal (HPI) axis. Corticotropin Releasing Factor (CRF) released by hypothalamus acts on the pituitary gland to synthesise and release the Adrenocorticotropic Hormone (ACTH) which, in turn, promotes the secretion of cortisol by interrenal tissue (homologous to the mammalian adrenal cortex) [6].

As a result of high levels of these hormones in the circulatory system, a wide range of secondary responses can be observed; particularly secondary responses are defined as the subsequent actions and effects of these hormones at both blood and tissue levels, and include disturbance of the metabolic and hydromineral balance [6].

The tertiary responses, which are determined by prolonged or chronic stress, induce a significant reduction of fish welfare and influence adversely fish growth, reproduction and immune responses [7].

A variety of haematological and biochemical measurements are used as indicators of stress in fish. Among the most frequently measured variables, there are levels of circulating corticosteroid hormones, mainly cortisol; this is widely used both as a long and short term primary stress indicator $[8,9]$.

Indicators of secondary effects of stress are very numerous but the most used is plasma or serum glucose level. Haematocrit value is, also, used as a stress index because it is simple and immediate to be determined.

Physiological responses to stress can vary depending on the type and duration of stressors [10-12] and species [8, 13, 14]. For example, elevation in plasma cortisol levels, which 
represents a typical response to stress, can differ by as much as two orders of magnitude among different species of fish following identical stressors [12, 15-17].

In this context, the AHAW (Animal Health and Welfare) Panel of European Food Safety Authority (EFSA) recommends that indicators of fish welfare are species-specific [18].

\subsection{Anaesthesia and Stress Response}

Anaesthesia is, by definition, a biological reversible state induced by an external agent, which results in the partial or complete loss of sensation or loss of voluntary neuromotor control, through chemical or non chemical means [19].

Anaesthesia is frequently applied in aquaculture being a valuable tool that helps to minimize fish stress and to prevent physical injuries to fish while handling them during routine practices. For example, anaesthesia is required for measuring or weighing fish, sorting and tagging, administrating vaccines, live transport, sampling for blood or gonadal biopsies and collecting of gametes, to cite some of the main applications.

A number of parameters have to be considered in the choice of an anaesthetic for fish [19]. A fish anaesthetic must, primarily, be effective: (i.e., it must have short induction and recovery times), be economical and harmless to both the user and environment and have limited side effects. However, when choosing an anaesthetic, it is important to take into consideration the type of the experiment and the species of fish $[19,20]$. So far, a number of different anaesthetics have been used or evaluated for aquaculture applications [19, 21-25].

Tricaine methanesulphonate (better known under the trade name of MS-222) is the most frequently used fish anaesthetic. This is the only approved by Food and Drug Administration (FDA) for use with edible fish in the USA, although fish treated with MS-222 must be held for a minimum of 21 days before human consumption. MS-222 is potent and effective in low concentrations but it is expensive and has a suspected carcinogen effect although no mutagen one has been documented [26].

Among fish anaesthetics, another compound that shows interesting features, in terms of both safety and efficacy, is clove oil. Clove oil is a distillate of the herbaceous portions of the clove tree, Eugenia caryophyllata (fam. Myrtaceae); its main constituent is eugenol (4-allyl-2-methoxyphenol), known for its anaesthetic properties and for use in human dentistry. Eugenol has been shown to be effective for anaesthesia in a variety of fish species [20, 27-30].

Although it was defined by FDA as a GRAS (Generally Recognised As Safe) product with human intake levels established at $2.5 \mathrm{mg} \mathrm{Kg}{ }^{-1} \mathrm{day}^{-1}$ [31] it has not yet been approved for use in edible fish.

Another primary feature that an anaesthetic should possess is the ability to mitigate the stress response [32] reducing or blocking activation of the HPI axis associated with handling stressors. In fact, failure to suppress stress-induced activation of HPI axis results in a release of cortisol hormone which in turn causes various physiological responses and the associated consequences.

Extensive studies on Teleost species have shown that cortisol and glucose stress responses to handling are usually reduced by previous treatment with anaesthetics [33-35]. However, literature reports conflicting data on the effects and dose-response relationship of exposure to anaesthetics.

Another important aspect to consider is related to systemic side effects induced by anaesthetic itself. In fact, although anaesthesia benefits fish by minimizing the impact of more severe stressors, it is also inherently stressful [3638].

Anaesthetics can influence fish physiology during induction of the "state of anaesthesia". This aspect has to be considered when blood or tissue samplings are made, because the values of physiological parameters could change as a result of anaesthetic effect during induction; this is especially important for physiological responses that occur rapidly (i.e., cortisol rise).

\subsection{Research Objectives}

This research was conducted on blackspot sea bream, Pagellus bogaraveo (Brünnich, 1768) and greater amberjack, Seriola dumerilii (Risso, 1810), two Teleost species considered important to diversification of farmed fish.

Moreover, while several studies on stress response to handling have been reported for some cultured marine fish (see [5] for a review), no research has been conducted on these two species in terms of comparison of various anaesthetics and their effects.

In particular the main objectives of this research were the following:

Trial 1: to compare the anaesthetic efficacy of MS-222 and clove oil in blackspot seabream and greater amberjack;

Trial 2: to compare the effects of MS-222 and clove oil on the physiology of greater amberjack juveniles after anaesthesia;

Trial 3: to determine whether MS-222 and clove oil were able to block the normal serum cortisol increase associated to handling stress in adult blackspot seabream.

Serum cortisol and glucose levels and haematocrit values were used as indicators of stress.

\section{MATERIALS AND METHODOLOGY}

\subsection{Rearing Conditions and Experimental Animals}

The study was carried out at the Experimental Aquaculture Plant of the Institute for Coastal Marine Environment (IAMC-CNR) of Messina, Italy.

Wild juveniles of blackspot sea bream, Pagellus bogaraveo and greater amberjack, Seriola dumerilii were chosen as studied species because of their importance to the diversification of farmed fish.

Prior to the study, fish were maintained in indoor tanks, provided with a flow-through supply of aerated seawater under natural photoperiodic conditions. 
P. bogaraveo was fed ad libitum a commercial diet (Hendrix S.p.a.) while $S$. dumerilii was fed a fresh diet consisting of anchovies and sardines.

\subsection{Trial 1: Comparative Efficacy of MS-222 and Clove Oil in Pagellus bogaraveo and Seriola dumerilii}

The experiment was carried out in different time periods but with the same experimental procedure.

Body weight (mean $\pm \mathrm{SD}$ ) of $P$. bogaraveo and $S$. dumerilii was $10.8 \pm 5.3 \mathrm{~g}$ and $288.22 \pm 96.56 \mathrm{~g}$ respectively.

To allow acclimatisation, one month before the beginning of the experiment, fish were randomly transferred in $2 \mathrm{~m}^{3}$ circular tanks, provided with a flow-through supply of aerated seawater.

Fish were fed to satiation daily, then they were fasted and human contact or disturbance was avoided for $24 \mathrm{~h}$ before the start of the experiments.

The tested anaesthetics were MS-222 (3-aminobenzoic acid ethyl ester methanesulfonate or tricaine methanesulfonate) and clove oil, both purchased from Sigma-Aldrich (Milano-Italy).

Due to clove oil's incomplete solubility in water, it was dissolved in ethanol at a 1:10 ratio $(\mathrm{v} / \mathrm{v})$, before being mixed in the anaesthetic tank.

To standardise the concentrations of anaesthetics used throughout the experiments, all the concentrations were expressed as $\mathrm{mg} \mathrm{L}^{-1}$ in relation to the concentration of active substance of each anaesthetic.

The tested concentrations were $70,80,90,100 \mathrm{mg} \mathrm{L}^{-1}$ for MS-222 and 10, 20, 30, $40 \mathrm{mg} \mathrm{L}^{-1}$ for clove oil.

The minimum concentration producing in all fish the total loss of muscle tone, within 3 minutes, and recovery to normal swimming within 10 minutes or less, was considered as the effective anaesthetic concentration.

Total loss of muscle tone is equivalent to light anaesthesia (stage III - plane 1) used by Stoskopf [24] and considered as the condition suitable for external sampling and biopsies (Table 1).

The experimental procedure was the following: each fish was transferred with a net to an anaesthetic tank consisting of 25-L glass aquaria (one for each anaesthetic). Each anaesthetic tank was filled with $20 \mathrm{~L}$ of sea water containing different concentrations of anaesthetics; these latter were tested from the lowest to highest one to ensure that any potential residue would influence the successive trials.

Salinity and temperature of sea water in anaesthetic tanks were 38 and $18^{\circ} \mathrm{C}$ and 38 and $16^{\circ} \mathrm{C}$ for blackspot sea-bream and greater amberjack, respectively.

The time taken by each fish to reach stage III anaesthesia ("induction time") was determined using a stopwatch.

Behavioural reaction to insertion of a hypodermic needle was observed to assess that analgesia was reached in each anaesthetised individual.
Following application of the anaesthesia, fish was immediately removed from the anaesthetic tank and placed in a tank containing only sea water; then the time needed to recover to normal conditions ("recovery time") was determined.

Fish were anaesthetised individually and a total of 60 fish were tested for each chemical.

The Shapiro-wilk test was applied to data for testing if they were normally distributed.

The correlation between induction time and fish weight for both each anaesthetic and concentration was examined using the regression analysis.

The effect of anaesthethic concentrations on both induction and recovery times was evaluated using the Analysis of Variance (ANOVA), followed by the Scheffe test when appropriate. Statistical analyses were performed with a Statistical Analysis Software (SAS).

Table 1. Stages of Anaestesia in Fish (from Stoskopf [24])

\begin{tabular}{|c|c|c|c|}
\hline \multicolumn{4}{|c|}{ STAGES OF ANAESTHESIA IN FISH } \\
\hline Stage & Plan & Category & Behavioural Response of fish \\
\hline 0 & & Normal & $\begin{array}{l}\text { Swimming actively; } \\
\text { Reactive to external stimuli; } \\
\text { Equilibrium normal; } \\
\text { Muscle tone normal. }\end{array}$ \\
\hline I & 1 & $\begin{array}{l}\text { Light } \\
\text { Sedation }\end{array}$ & $\begin{array}{l}\text { Voluntary swimming continues; } \\
\text { Slight loss of reactivity to visual and } \\
\text { tactile stimuli; } \\
\text { Respiratory rate normal; } \\
\text { Equilibrium normal; } \\
\text { Muscle tone normal. }\end{array}$ \\
\hline I & 1 & $\begin{array}{l}\text { Light } \\
\text { Narcosis }\end{array}$ & $\begin{array}{c}\text { Excitement phase may precede increase } \\
\text { in respiratory rate; } \\
\text { Loss of equilibrium; } \\
\text { Efforts to right itself; } \\
\text { Muscle tone decreased; } \\
\text { Still responds to positional changes } \\
\text { weakly. }\end{array}$ \\
\hline II & 2 & $\begin{array}{l}\text { Deep } \\
\text { Narcosis }\end{array}$ & $\begin{array}{c}\text { Ceases to respond to positional } \\
\text { changes; } \\
\text { Decrease in respiratory rate to near } \\
\text { normal; } \\
\text { Total loss of equilibrium; } \\
\text { No effort to right itself; } \\
\text { Muscle tone decreased; } \\
\text { Some reactivity to strong tactile and } \\
\text { vibrational stimuli; } \\
\text { Suitable for external sampling, fin and } \\
\text { gill biopsies. }\end{array}$ \\
\hline III & 1 & $\begin{array}{l}\text { Light } \\
\text { Anaesthesia }\end{array}$ & $\begin{array}{c}\text { Total loss of muscle tone; } \\
\text { Responds to deep pressure; } \\
\text { Further decrease in respiratory rate; } \\
\text { Suitable for minor surgery }\end{array}$ \\
\hline III & 2 & $\begin{array}{c}\text { Surgical } \\
\text { Anaesthesia }\end{array}$ & $\begin{array}{c}\text { Total loss of reactivity; } \\
\text { Respiratory rate very low; } \\
\text { Heart rate slow. }\end{array}$ \\
\hline IV & & $\begin{array}{l}\text { Medullary } \\
\text { Collapse }\end{array}$ & $\begin{array}{l}\text { Total loss of gill movement followed in } \\
\text { several minutes by cardiac arrest. }\end{array}$ \\
\hline
\end{tabular}


2.3. Trial 2: Comparison of MS-222 and Clove Oil Anaesthesia Effects on the Physiology of Seriola dumerilii Juveniles

Three groups of greater amberjack juveniles (each composed of $n=15$ fish with mean body weight \pm SD: 288.22 $\pm 96.56 \mathrm{~g}$ ) were compared in this study: control (unanaesthetized), MS-222-anaesthetised and clove oil-anaesthetised.

The concentrations of the used anaesthetic were those established in the trial 1 (MS-222: $100 \mathrm{mg} \mathrm{L}^{-1}$; clove oil: 40 $\mathrm{mg} \mathrm{L}^{-1}$ ). One month before the start of the experiment, fish were acclimatised in $2-\mathrm{m}^{3}$ circular tanks and fed to satiation daily. Fish were fasted and left undisturbed for $24 \mathrm{~h}$ before the start of the experiment.

Anaesthetic baths (glass aquaria) were prepared taking into consideration the volume of water $(25-\mathrm{L})$ in order to reach the final concentration of MS-222 or clove oil desired in the exposure tank. The water in the tank was mixed manually with a glass rod, to allow a homogeneous distribution of the anaesthetic before fish exposure. In order to ensure the correct exposure of specimens to chemicals, anaesthetic bath was changed every five fish.

The experimental procedure was the following: fish were placed individually in the anaesthetic concentration. Following induction of light anaesthesia (stage III - plane 1, see trial 1 and Table 1), just before being transferred in the recovery tank, fish were immediately bled from the caudal vein. The control group was sampled in $<30$ seconds and fish belonging to this group were considered as a negative control for comparison with anaesthetised fish. After bleeding, fish were placed into a tank containing fresh, aerated sea water for recovery.

Differences between groups were determined using the Analysis of Variance (ANOVA), followed by the Duncan test at a significance level of $\mathrm{P} \leq 0.05$.

2.4. Trial 3: Comparison of MS-222 and Clove Oil Anaesthesia on Stress Response to Handling Stress in Pagellus bogaraveo Adults

Ninety-six adult specimens of $P$. bogaraveo (mean body weight $\pm \mathrm{SD}, 302.70 \pm 23.36 \mathrm{~g}$ ) were randomly distributed in four groups of 24 fish: 1) two groups pre-treated respectively with an immobilizing dose of MS-222 (100 $\left.\mathrm{mg} \mathrm{L}^{-1}\right)$ or clove oil (40 $\left.\mathrm{mg} \mathrm{L}^{-1}\right)$ and exposed to handling stress; 2) a group subjected to the same stress but without a preliminary anaesthesia; 3) a control group was kept undisturbed.

The procedure for each experimental group was as follows: interruption of water-flow, introduction of the anaesthetic solution in tank and application of stressors after the fish were anaesthetised. The latter consisted in transferring fish from one tank to another one and exposing them to air for 2 minutes.

Blood samples were collected from the caudal vein at the time of transfer (time 0 ) and 15, 30 and 60 minutes after the start of exposure to stress. To avoid a sampling-induced stress response, withdrawal lasted less than 3-4 minutes for group, since it was carried out simultaneously by two operators.
Data were analysed using the Analysis of Variance (ANOVA), followed by the Duncan test at a significance of $\mathrm{P} \leq 0.05$.

\subsection{Analytical Procedures}

In order to extract the serum for the determination of cortisol and glucose, blood samples not treated with heparin, were allowed to clot at $4^{\circ} \mathrm{C}$, centrifuged at $1500 \mathrm{~g}$ for 10 minutes and stored at $-80^{\circ} \mathrm{C}$ until analysis.

Small volumes of blood collected in heparinised (14 International Unit $\mathrm{ml}^{-1}$ ) tubes, were used for the immediate determination of haematocrit values.

Serum cortisol concentrations were determined by use of a commercially available enzyme-linked (ELISA) immunoassay kit (Alpha Diagnostic International, USA).

Serum glucose levels were determined by a commercial kit based on the reaction of GOD-POD (Glucose OxidasePeroxidase) (Sclavo Diagnostics, Italy).

Haematocrit as the percentage of red blood cell to the total blood volume, was determined in heparinised capillary tubes, after centrifugation in a standard microhaematocrit centrifuge at $12.000 \mathrm{~g}$ for 10 minutes, and comparison of capillary tubes with a reference scale.

\section{RESULTS}

\subsection{Trial 1: Comparative Efficacy of MS-222 and Clove Oil in Pagellus bogaraveo and Seriola dumerilii}

No mortality was observed during anaesthesia or $24 \mathrm{hrs}$ after it in both the anaesthetic treatments. The induction and recovery times (mean \pm SD) of fish exposed to MS-222 or clove oil are shown in Table 2.

Table 2. Induction and Recovery Times of Different Anaesthetics in $P$. bogaraveo and $S$. dumerili (Mean \pm SD), $n=15$. For each Anaesthetic, Statistically Significant Differences $(P<0.01)$ Recorded in the Induction and Recovery Times in Relation to the Different Tested Concentrations are Indicated By Superscripts

\begin{tabular}{|c|c|c|}
\hline $\begin{array}{l}\text { Anaesthetic } \\
\text { Concentration }\end{array}$ & $\begin{array}{c}\text { Induction Time } \\
\text { (minutes) }\end{array}$ & $\begin{array}{l}\text { Recovery Time } \\
\quad \text { (minutes) }\end{array}$ \\
\hline \multicolumn{3}{|c|}{ Pagellus bogaraveo } \\
\hline \multicolumn{3}{|l|}{ MS-222 $\left(\mathrm{mgL}^{-1}\right)$} \\
\hline 70 & $4.73 \pm 1.71^{\mathrm{A}}$ & $1.73 \pm 0.27^{\mathrm{A}}$ \\
\hline 80 & $3.69 \pm 0.58^{\mathrm{B}}$ & $1.25 \pm 0.49^{\mathrm{A}}$ \\
\hline 90 & $2.65 \pm 0.52^{\mathrm{C}}$ & $1.49 \pm 0.76^{\mathrm{A}}$ \\
\hline 100 & $1.91 \pm 0.70^{\mathrm{D}}$ & $1.22 \pm 0.60^{\mathrm{A}}$ \\
\hline \multicolumn{3}{|l|}{ Clove Oil $\left(\mathrm{mgL}^{-1}\right)$} \\
\hline 10 & $>15^{\mathrm{A}}$ & $6.87 \pm 2.74^{\mathrm{A}}$ \\
\hline 20 & $4.04 \pm 0.58^{\mathrm{B}}$ & $2.62 \pm 0.92^{\mathrm{B}}$ \\
\hline 30 & $2.86 \pm 0.63^{\mathrm{C}}$ & $3.02 \pm 1.13^{\mathrm{B}}$ \\
\hline 40 & $1.88 \pm 0.65^{\mathrm{C}}$ & $3.54 \pm 1.45^{\mathrm{B}}$ \\
\hline
\end{tabular}


(Table 2) Contd.....

\begin{tabular}{|c|c|c|}
\hline $\begin{array}{c}\text { Anaesthetic } \\
\text { Concentration }\end{array}$ & $\begin{array}{c}\text { Induction Time } \\
\text { (minutes) }\end{array}$ & $\begin{array}{c}\text { Recovery Time } \\
\text { (minutes) }\end{array}$ \\
\hline \hline \multicolumn{3}{|c|}{ Seriola dumerilii } \\
\hline MS-222 $\left(\mathbf{m g L}^{-\mathbf{1}}\right)$ & & $2.62 \pm 0.25^{\mathrm{A}}$ \\
\hline 70 & $5.71 \pm 1.65^{\mathrm{A}}$ & $2.20 \pm 0.50^{\mathrm{A}}$ \\
\hline 80 & $4.65 \pm 0.78^{\mathrm{B}}$ & $2.46 \pm 0.72^{\mathrm{A}}$ \\
\hline 90 & $3.60 \pm 0.70^{\mathrm{C}}$ & $2.39 \pm 0.45^{\mathrm{A}}$ \\
\hline 100 & $2.59 \pm 0.55^{\mathrm{D}}$ & $7.77 \pm 2.70^{\mathrm{A}}$ \\
\hline Clove Oil (mgL & & $2.52 \pm 0.82^{\mathrm{B}}$ \\
\hline 10 & $>15^{\mathrm{A}}$ & $3.00 \pm 1.08^{\mathrm{B}}$ \\
\hline 20 & $4.04 \pm 0.58^{\mathrm{B}}$ & $3.50 \pm 1.39^{\mathrm{B}}$ \\
\hline 30 & $2.86 \pm 0.63^{\mathrm{C}}$ & \\
\hline 40 & $2.40 \pm 0.45^{\mathrm{C}}$ & \\
\hline
\end{tabular}

No correlations between fish weight and induction time were observed for both the species.

Both in blackspot seabream and greater amberjack, anaesthesia induction times decreased with increasing concentrations of MS-222 and clove oil.

For MS-222, induction times obtained with all the concentrations were significantly ( $\mathrm{p} \leq 0.01)$ different to each other; instead, for clove oil, induction times observed at 10 and $20 \mathrm{mg}$ were significantly $(\mathrm{p} \leq 0.01)$ different to each other while there were no differences between those recorded using 30 and $40 \mathrm{mg}$ (Table 2).

On the other hand, recovery times were concentration independent. However, for both the species, there were significant $(\mathrm{p} \leq 0.01)$ differences in recovery times following exposure to $10 \mathrm{mg}$ of clove oil.

The concentration of MS-222 and clove oil found to be effective in blackspot seabream and greater amberjack was $100 \mathrm{mg} \mathrm{L}^{-1}$ and $40 \mathrm{mg} \mathrm{L}^{-1}$, respectively.

\subsection{Trial 2: Comparison of MS-222 and Clove Oil Anaesthesia Effects on the Physiology of Seriola dumerilii Juveniles}

Fig. (1) shows the changes in serum cortisol, glucose and haematocrit values after exposure of greater amberjack juveniles to MS-222 or clove oil.

Serum cortisol levels of anaesthetised fish (with both anaesthetics) were significantly $(\mathrm{p} \leq 0.01)$ higher than control values (Fig. 1A). However there were no significant differences in serum cortisol levels between fish exposed to MS-222 (100 $\left.\mathrm{mg} \mathrm{L}^{-1}\right)$ and clove oil $\left(40 \mathrm{mg} \mathrm{L}^{-1}\right)$.

Clove oil group displayed a significant increase in serum glucose levels compared to controls or MS-222 anaesthetized fish (Fig. 1B).

Finally, haematocrit levels of anaesthetised fish were significantly $(\mathrm{p}<0.01)$ higher than controls (Fig. 1C), while
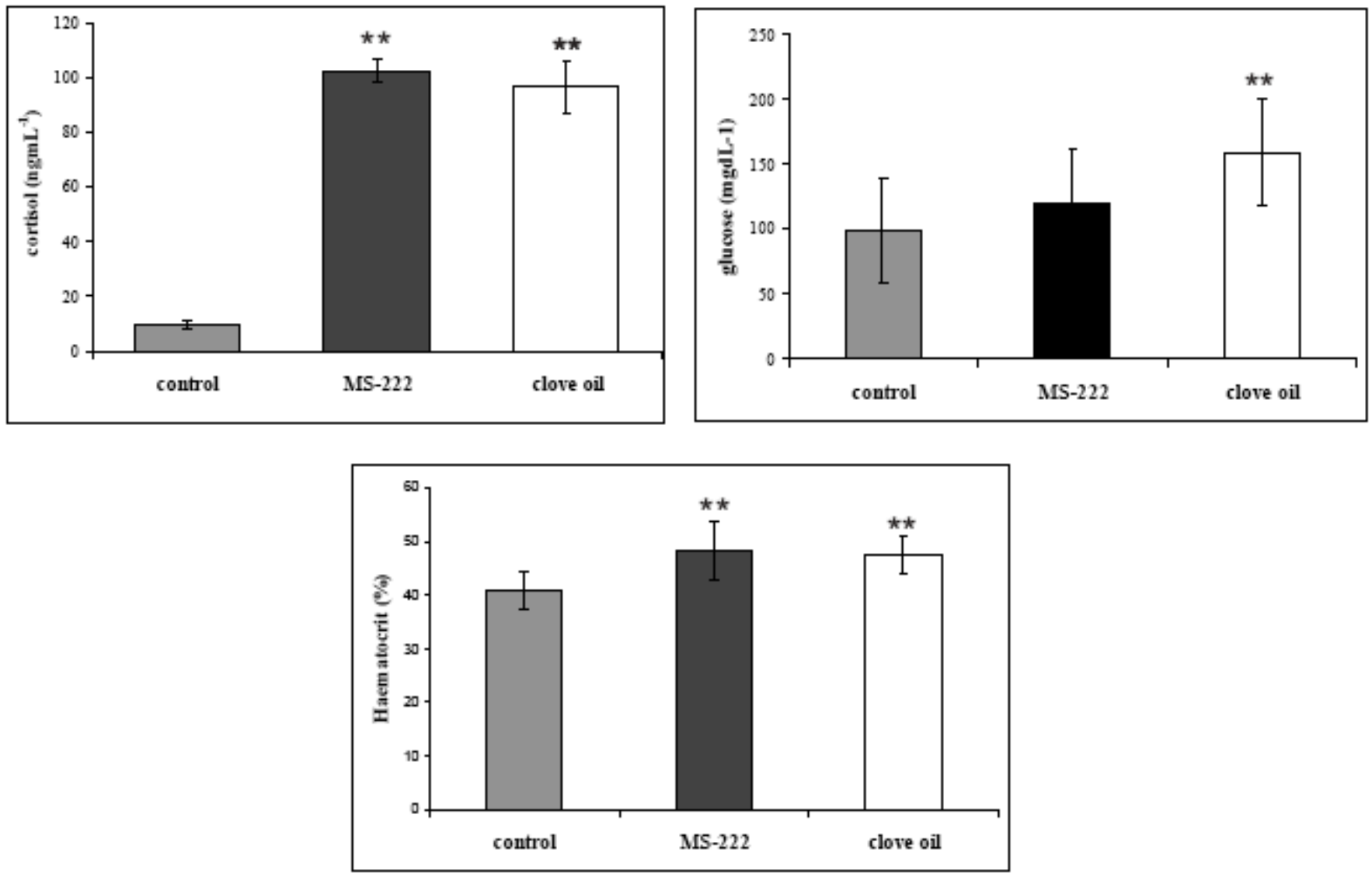

Fig. (1). Measurements of some physiological parameters (mean \pm SD) in $S$. dumerilii juveniles anaesthetised in MS-222 or in clove oil. (A): serum cortisol; $(\mathbf{B})$ : serum glucose; $(\mathbf{C})$ : haematocrit. Asterisks indicate significant differences between groups $(* * \mathrm{P} \leq 0.01)$. 
no differences were found between MS-222 and clove oiltreated fish.

\subsection{Trial 3: Comparison of MS-222 and Clove Oil Anaesthesia on Stress Response to Handling Stress in $\boldsymbol{P}$. bogaraveo Adults}

Transfer of tank and exposure to air for 2 minutes elicited in $P$. bogaraveo a marked elevation of cortisol and glucose in both the control and anaesthetised groups treated with both the tested anaesthetics.

In Figs. (2 and 3) the effects of anaesthetics on cortisol and glucose response to handling stress are shown.

Serum cortisol markedly increased 15 minutes after handling stress, and the peak was detected 30 minutes after handling, when cortisol reached a maximum concentration of $292.38 \pm 183.31,235.93 \pm 116.02$ and $213.14 \pm 41.87 \mathrm{ng}$ $\mathrm{mL}^{-1}$ in clove oil, MS-222 and control groups, respectively. There were no significant differences in cortisol levels between either of these groups.

Cortisol levels decreased significantly $(\mathrm{P} \leq 0.01) \quad 60$ minutes after handling, returning to the initial values measured before handling, in both anaesthetised groups. In fact, cortisol concentrations were $126.43 \pm 93.41$ and $104.81 \pm$ $60.49 \mathrm{ng} \mathrm{mL}^{-1}$ in clove oil and MS-222 groups, respectively.

On the contrary, in the control group, cortisol levels continued to increase and differences between anaesthetised and control groups were significant.

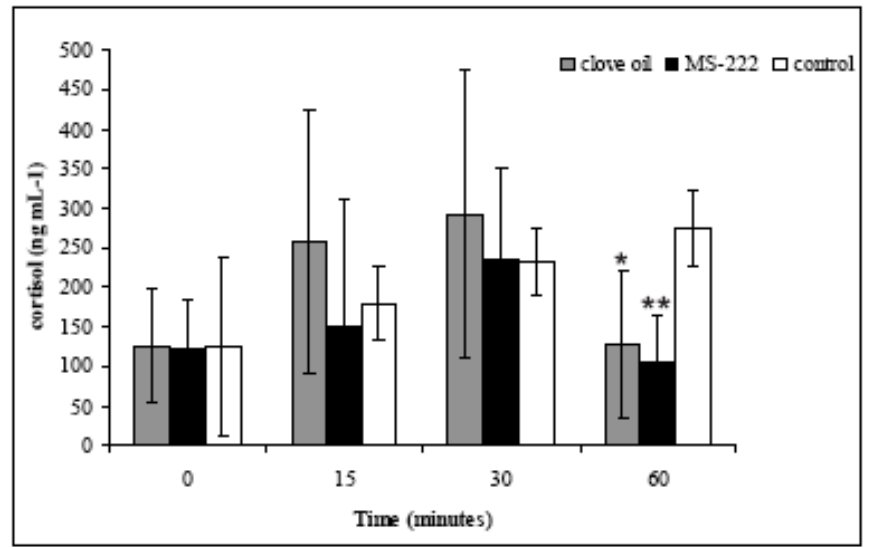

Fig. (2). Effects of anaesthetics on cortisol response in $P$. bogaraveo after handling stress. Asterisks indicate significant differences between groups $(* * \mathrm{p} \leq 0.01 ; * \mathrm{p} \leq 0.05)$.

Serum glucose markedly increased 15 minutes after stress and the peak was detected 30 minutes after stress, when glucose reached a maximum concentration of $141.02 \pm$ $44.42,130.01 \pm 21.23$ and $139.37 \pm 32.18 \mathrm{mg} \mathrm{dL}^{-1}$ in clove oil, MS-222 and control groups, respectively. There were no significant differences in cortisol levels between either of these groups.

Afterward, glucose levels decreased in both the anaesthetized groups, although no recovery to initial values was observed. In fact, glucose maintained concentrations of $102.42 \pm 25.73$ and $113.90 \pm 23.77 \mathrm{mg} \mathrm{dL}^{-1}$ respectively in clove oil and MS-222 groups, respectively. On the contrary, in the control group, glucose concentration continued to increase, reaching $155.32 \pm 35.78 \mathrm{mg} \mathrm{dL}^{-1}$.
Differences between anaesthetised and control groups were significant $(\mathrm{p} \leq 0.05) 60$ minutes after handling.

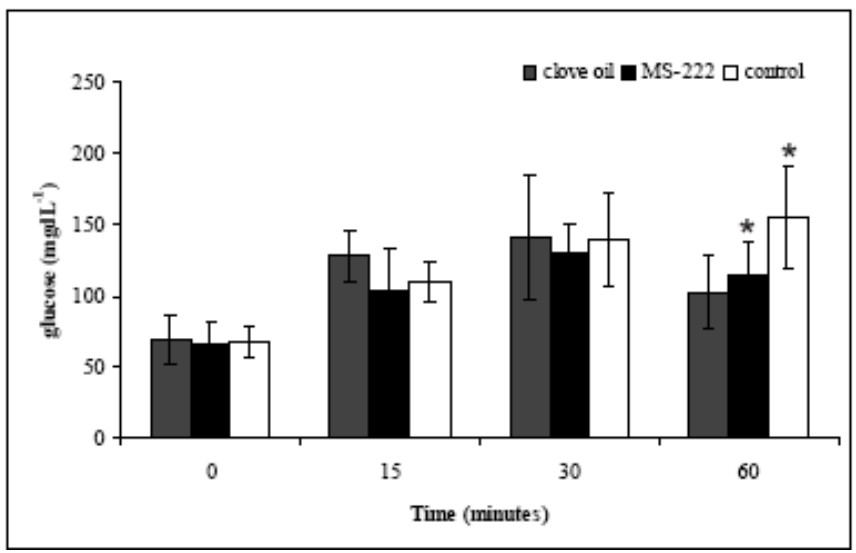

Fig. (3). Effects of anaesthetics on glucose response in $P$. bogaraveo after handling stress. Asterisks indicate significant differences between groups $(* \mathrm{p} \leq 0.05)$.

\section{DISCUSSION}

\subsection{Trial 1: Comparative Efficacy of MS-222 and Clove Oil in P. bogaraveo and $S$. dumerilii}

This trial examined the efficacy of clove oil, in comparison with MS-222, as an anaesthetic for wild juveniles of $P$. bogaraveo and $S$. dumerilii and assessed the minimum concentration producing the desirable anaesthetic effects.

There is no simple definition of efficacy for fish anaesthetics, although many of published papers define this as the ability to handle the fish.

Generally, an ideal anaesthetic should induce anaesthesia rapidly and allow a speed recovery, should not be toxic, should leave low tissue residues and be inexpensive [22, 23].

In our study we assumed as criteria of efficacy the ability to induce anaesthesia (stage III - plane 1) within 3 minutes and to allow recovery within 10 minutes or less.

The obtained results have shown that clove oil acts as an anaesthetic in the juveniles of both $P$. bogaraveo and $S$. dumerilii.

Blackspot sea bream and greater amberjack specimens exposed to clove oil progressed sequentially through the stages of anaesthesia outlined by Stoskopf [24].

Like MS-222, the increase in clove oil concentration, produced a reduction in the time required by fish to reach stage III-plane 1 anaesthesia.

The sequential passage of fish through the stages of anaesthesia together with the concentration and duration of the observed exposure effects, indicate that clove oil acts as "true" anaesthetic [30, 39].

The analgesic effect of clove oil comes from the inhibition of prostaglandin $\mathrm{H}$ synthase (PHS) by eugenol, the active ingredient of clove oil [30].

Eugenol has shown to immobilize fish at a concentration, lower than MS-222 (40 mg L${ }^{-1}$ instead of $\left.100 \mathrm{mg} \mathrm{L}^{-1}\right)$. 
Similar results were obtained by Mylonas et al. [40] which showed that a concentration of $40 \mathrm{mg} \mathrm{L}^{-1}$ clove oil was able to anaesthetize both juvenile gilthead sea bream $\left(25^{\circ} \mathrm{C}\right.$, weight $\left.41.9 \mathrm{~g}\right)$ and sea bass $\left(25^{\circ} \mathrm{C}\right.$, weight $\left.32.5 \mathrm{~g}\right)$ within $3 \mathrm{~min}$. Conversely, Endo et al. [41] showed that a concentration of $25 \mathrm{mg} \mathrm{L}^{-1}$ is required to anaesthetize rainbow trout $\left(14^{\circ} \mathrm{C}\right.$, weight $\left.12 \mathrm{~g}\right)$.

It seems that the highest efficacy of eugenol compared to MS-222, in this study, is due to the oil's high lipid solubility [30]. In addition to efficacy, clove oil has several benefits.

Eugenol has been widely tested for human use and consumption (as anaesthetic in dentistry, as a flavor ingredient in food) and is considered not toxic or carcinogen in mammals [29, 30] but rather, it may have anticarcinogenic properties [42].

Clove oil has not yet been approved for use in fish destined to human consumption by FDA, but AQUI-S ${ }^{\mathrm{TM}}$, an anaesthetic with chemical composition similar to clove oil (50\% isoeugenol), was approved in New Zealand and Australia, as a fish anaesthetic with no withdrawal time, and work for its approval both in USA and Scandinavia was made [43].

\subsection{Trial 2: Comparison of MS-222 and Clove Oil Anaesthesia Effects on the Physiology of Seriola dumerilii Juveniles}

This trial examined the physiological responses of greater amberjack juveniles to anaesthesia with MS-222 and clove oil.

In the research on fish anaesthesia, an important aspect to be considered is whether the anaesthetic by itself generates stress.

In mammals it is known that anaesthesia, induced by certain chemical substances (i.e., diethyl ether), produce stress because activation of HPI axis; conversely, other anaesthetic agents (i.e., barbiturates) are not stressful [44, 45].

Similarly to mammals, also in fish, anaesthesia can have a physiological impact that varies according to the anaesthetic agent [38].

Most of researches carried out to evaluate anaesthetics in relation to their stress response use cortisol and glucose as stress indicators [7, 46, 47] and a number of anaestheticinduced increases in cortisol have been observed in several species [48-51].

Many studies were performed on MS-222, being the most used anaesthetic in aquaculture [37, 38, 52-55]; in contrast, researches on clove oil, especially on its physiological effects, are a few only $[50,51,56]$.

It is known that MS-222 anaesthesia induces activation of HPI axis and its related metabolic consequences, and affects parasympathetic system resulting in an increase of both cardiac frequency and ventilatory rhythm [36, 54]. Moreover, MS-222 is an hypoxic agent; this causes a depression of medullary respiratory centre which is associated with several physiological changes including bradycardia, erythrocytes swelling and increased resistance of blood flow trough the gill lamellae [57-59].
In greater amberjack juveniles, physiological changes in serum cortisol levels and haematocrit values following exposure to clove oil, were indistinguishable from changes associated with exposure to MS-222.

Serum cortisol levels increased in greater amberjack exposed to MS-222 or clove oil.

These results are consistent with most of reports on anaesthesia in fish. Strange \& Schreck [37] found that an immobilizing dose of MS-222 was capable of eliciting an immediate cortisol response; Barton \& Peters [60] reported a cortisol increase in larvae after anaesthesia. Conversely, Iwama et al. [38] showed that anaesthesia in general produced a downward trend in plasma cortisol throughout induction and recovery.

Also haematocrit values increased in $S$. dumerilii after anaesthesia with MS-222 or clove oil.

Increase in haematocrit is a symptom of hemoconcentration that is one of the most common consequences of anaesthesia.

Literature reports haemoconcentration in fish anaesthetized with both tricaine $[53-55,61]$ and clove oil $[50,56]$.

The mechanism of action responsible for haematocrit increase is unknown, but the rapidity of the response supports the hypothesis of splenic contraction that causes an increase in red blood cell number [62].

Blood glucose concentration increased in greater amberjack anaestethized with clove oil but not with MS-222.

Sladky et al. [56] reported a rapid increase of blood glucose concentration in red pacu (Piaractus brachypomus) after anaesthesia with MS-222 or clove oil. The authors hypothesized that, similarly to what occurs in mammals, this sudden increase of glucose levels was due to catecholamineinduced gluconeogenesis.

However, a transient decrease in blood glucose concentration has also been observed by some authors [36, 63] immediately after induction of MS-222 anaesthesia. This results has led to conclude that tricaine did not alter carbohydrate metabolism in fish.

In our study is likely that this initial decrease of glucose levels occurred, while the hyperglycemia was not observed because MS-222 anaesthesia was rapidly induced (about 3 $\min )$ and therefore it probably occurred afterwards.

Although the assessment of the cardiovascular functions was not included in the aims of our study we observed that fish exposed to clove oil may have an impairment of cardiovascular system.

Collection of blood by means of caudal puncture was subjectively assessed to be more difficult in greater amberjack anaesthetised with clove oil than in those anaesthetised with MS-222.

Similar considerations were made by Sladky et al. [56] in red pacu (Piaractus brachypomus) anaesthetised with clove oil or MS-222. Authors concluded that this difficulty in blood withdrawal suggests hemodynamic instability or insufficient oxygen loading or delivery, probably associated with decreased arterial blood pressure. 
One of the most common side-effects of anaesthetics is the reduced ventilation and circulation.

Moreover, clove oil has been reported to reduce gill ventilation because of depression of medullary respiratory centres, bradycardia and decreased blood flow through the gills [39].

\subsection{Trial 3: Comparison of MS-222 and Clove Oil Anaesthesia on Cortisol Responsiveness to Handling Stress}

This trial examined the ability of MS-222 and clove oil to avoid the normal serum cortisol increase associated to handling stress in adults of $P$. bogaraveo.

Handling is an inherently stressful event [64-66]. Removal from the water elicits a maximal physiological emergency and evokes a neuroendocrine stress response in many species of farmed fish [67]; in S. aurata air exposure for 3 min resulted in a 50-fold increase in plasma cortisol levels within $30 \mathrm{~min}$ [68].

Where handling is prolonged, such as during stripping and milking, sedation or anaesthesia is recommended [69, 70].

Therefore, when selecting an anaesthetic, it is important to evaluate its stress-reducing capacity that is the ability to block the HPI axis and make the fish unable to respond to additional stressors $[30,71]$.

A transitory elevation of cortisol (with a maximum concentration at 15-30 min and recovery to initial levels by $90 \mathrm{~min}$ ) is a common response of Teleosts to an acute stress $[37,64]$.

The increase in cortisol levels and the hyperglycemia, typical of acute stress response, were observed in all the experimental groups exposed to handling stressor.

Cortisol values obtained in the present study indicate that anaesthetised fish are also affected by handling, but to a lesser extent than not anaesthetised fish.

However anaesthesia has proved to be effective to mitigate the duration of stress response; indeed, $60 \mathrm{~min}$ after handling, cortisol levels decreased in both clove oil and MS-222 groups unlike the control in which, at this time, this hormone was still high.

Similarly, blood glucose levels were different between control and anaesthetised group suggesting, also in this case, the mitigating effect of anaesthetics.

The effect of anaesthesia, however, can be considered positive if we consider, as reported in literature, the duration of stress response to handling.

Morales at al. in a research on physiological responses to stress of common dentex (Dentex dentex) [72] reported that plasma glucose and lactate levels rise, as consequence of handling, but the recovery to basal levels occurs 8 hours after stress. Similarly, Rotland et al. [73] reported that, in Sparus aurata, blood cortisol returned to normal values 4 hours after handling.
The magnitude and duration of neuroendocrine response can vary between species and depends on the intensity and type of stress $[10,13,14]$.

Presumably, in this trial, the intensity of stress (transfer of tank and 2 minutes of air exposure) experienced by $P$. bogaraveo was very high and this prevented the recovery of glucose to initial levels.

Moreover, previous studies about the effectiveness of anaesthesia on handling stress in adults of $P$. bogaraveo [74], had highlighted the ability of MS-222 to prevent the activation of HPI axis; in this case, however, anaesthesia protocol was different (individual anaesthesia in 30-liters tanks vs. group anaesthesia in 2000-liters tanks) and the induced stress was lower (handling vs. handling and hypoxia).

The obtained results can be considered positive even if further studies are needed to develop efficient and reproducible anaesthetic protocols for the handling of $P$. bogaraveo.

\section{CONCLUSIONS}

This study contributes to increase knowledge on Pagellus bogaraveo and Seriola dumerilii, two species of interest for diversification of farmed fish, analysing two aspects not yet reported in literature for either the species, namely the stress response and the use of anaesthesia.

We have compared MS-222, the most popular anaesthetic used in aquaculture, with a new one, clove oil, not yet sufficiently investigated.

According to the results of induction and recovery times observed in the present investigation it can be concluded that clove oil is a good anaesthetic for both the examined species.

The minimum desirable concentration for anaesthesia which resulted in a total loss of equilibrium and muscular tone (light anaesthesia) in all the fish within 3 min, was determined to be $40 \mathrm{mg} \mathrm{L}^{-1}$ for both the species (Trial 1); to obtain the same results, $100 \mathrm{mg} \mathrm{L}^{-1}$ of MS-222 are necessary.

Moreover, the results obtained in trial 2 showed that clove oil does not affect both serum cortisol and glucose levels, differently from MS-222 in the anaesthetised fish.

According to these results clove oil seems to have interesting characteristics as an anaesthetic for both blackspot sea bream and greater amberjack. It is relatively cheap and can provide a plan of anaesthesia suitable for external sampling, fin and gill biopsies. Furthermore clove oil is easily obtained and is composed of organic substances safe for both environment and user.

One aspect that needs further researches concerns the stress-reducing capability of both MS-222 and clove oil.

Both anaesthetics proved to be unable to block activation of the HPI axis that occurs following handling stress in adults of $P$. bogaraveo, although a reduction of the duration of stress response was observed.

These results confirm that fish stress response, other than species-specific, is also affected by the duration and severity of the applied stress. In fact in previous studies MS-222 
anaesthesia proved to be effective in preventing cortisol and glucose increase in $P$. bogaraveo subjected to handling stress although of a lower intensity than that experienced in the present study.

Further studies however are needed to know how $P$. bogaraveo reacts to routine practices in aquaculture and develop efficient and reproducible anaesthetic protocols.

\section{REFERENCES}

[1] FAO (Food and Agriculture Organisation). The state of World Fisheries and Aquaculture, FAO, Rome 2004.

[2] Broom DM. Welfare, stress and the evolution of feeling. Adv Stud Behav 1998; 27: 371-403.

[3] Southgate P, Wall T. Welfare of farmed fish at slaughter. In Pract 2001; 23: 277-84.

[4] FSBI [Fisheries Society of the British Isles] [Homepage on the Internet]. Fish Welfare. Breifing Report 2. Granta Information system 2002. Available from: http://www.le.ac.uk/biology/ fsbi/welfare.pdf.

[5] Ashley PJ. Fish welfare: current issue in aquaculture. Appl Anim Behav Sci 2007; 104: 199-235.

[6] Wendelaar-Bonga SEW. The stress response in fish. Physiol Rev 1997; 77: 591-625.

[7] Pickering AD, Pottinger TG. Stress response and disease resistance in salmonid fish: effects of chronic elevation of plasma cortisol. Fish Physiol Biochem 1989; 7: 253-8.

[8] Pickering AD, Pottinger TG, Christie P. Recovery of the brown trout, Salmo trutta L., from acute handling stress: a time course of study. J Fish Biol 1982; 20: 229-44.

[9] Pickering AD, Pottinger TG. Acclimation of the brown trout (Salmo trutta) to the stress of daily exposure to malachite green. Aquaculture 1985; 44: 145-52.

[10] Pickering AD. Rainbow trout husbandry-management of stress response. Aquaculture 1992; 100: 125-39.

[11] Wedemeyer G. Effects of rearing conditions on the health and physiological quality of fish in intensive culture. In: Iwama G, Pickering A, Sumpter J, Schreck C, Eds. Fish Stress and Health in Aquaculture. Cambridge: Cambridge University Press 1997; pp. 35-72.

[12] Conte FS. Stress and Welfare of cultured fish. Appl Anim Behav Sci 2004; 86: 205-23.

[13] Wedemeyer GA. Physiological response of juvenile coho salmon (Onchorhyncus kisutch) and rainbow trout (Salmo gairdneri) to handling and crowding stress in intensive fish culture. J Fish Res Board Can 1976; 33: 2699-702.

[14] Davis KB, Parker NC. Plasma corticosteroid and chloride dynamics in rainbow trout, Atlantic salmon, and lake trout during and after stress. Aquaculture 1983; 32: 189-94.

[15] Barton BA. Salmonid fishes differ in their cortisol and glucose responses to handling and transport stress. N Am J Aquacult 2000; 62: 12-8.

[16] Barton BA. Stress in fishes: a diversity of responses. Am Zool 2000; 40: 937-1937.

[17] Congleton JL, LaVoie WJ, Schreck CB, Davis LE. Stress indices in migrating juvenile Chinook salmon and steelhead of wild and hatchery origin before and after barge transportation. Trans Am Fish Soc 2000; 129: 946-61.

[18] Scientific Opinion of the Panel on Animal Health and Welfare on a request from European Commission on General approach to fish welfare and to the concept of sentience in fish. EFSA J 2009; 954: $1-26$.

[19] Summerfield RC, Smith LS. Anesthesia, surgery and related tecniques. In: Schreck CB, Moyle PB, Eds. Methods in Fish Biology. Bethesda: American Fisheries Society 1990; pp. 213-72.

[20] Munday PL, Wilson SK. Comparative efficacy of clove oil and other chemicals in anesthetisation of Pomacentrus amboinensis, a coral reef fish. J Fish Biol 1997; 51: 931-8.

[21] Sehdev HS, McBride JR, Fagerland UHM. 2-Phenoxyethanol as a general anaesthetic for sockeye salmon. J Fish Res Board Can 1963; 20(6): 1435-40.

[22] Marking LL, Meyer FP. Are better anaesthetics needed in fisheries?. Fisheries 1985; 10(6): 2-5.
[23] Gilderhus PA, Marking LL. Comparative efficacy of 16 anaesthetic chemicals on rainbow trout. N Am J Fish Manage 1987; 7: 288-92.

[24] Stoskopf M. Anaesthesia. In: Brown L, Ed. Aquaculture for Veterinarians: fish husbandry and medicine. New York: Pergamon Press 1993; pp. 161-7.

[25] Ross LG, Ross B. Anaesthetics and sedative techniques for aquatic animals. Blackwell Science Ltd, London 1997; pp. 21-8.

[26] Yoshimura $H$, Nakamura $M$, Koeda T. Mutagenic screen of anaesthetics for fishes. Mut Res 1981; 90: 119-24.

[27] Hisaka H, Takase K, Ogasawara S. Anaesthesia and recovery with tricaine methanesulphonate, eugenol and thiopental sodium in the carp, Cyprinus carpio. Jpn J Vet Sci 1986; 48: 341-51.

[28] Soto CG, Burhanuddin CG. Clove oil as fish anaesthetic for measuring length and weight of rabbitfish (Siganus lineatus). Aquaculture 1995; 136: 149-52.

[29] Anderson WG, McKinley RS, Colavecchia M. The use of clove oil as anaesthetic for rainbow trout and its effects on swimming performance. N Am J Fish Manage 1997; 17: 301-7.

[30] Keene JL, Noakes DL, Moccia RD, Soto CG. The efficacy of clove oil as an anaesthetic for rainbow trout, Oncorhyncus mykiss (Walbaum). Aquaculture Res 1998; 29: 89-101.

[31] Expert Committee on Food Additives. Evolution of certain food additives and contaminants. WHO (World Health Organisation). Technical Report Series 20, 1992.

[32] Mommsen TP, Vijayan MM, Moon TW. Cortisol in teleosts: dynamics, mechanism of action and metabolic regulation. Rev Fish Biol Fisheries 1999; 9: 211-68.

[33] Thomas P, Robertson L. Plasma cortisol and glucose stress responses of red drum (Sciaenops ocellatus) to handling and shallow water stressors and anaesthesia with MS-222, quinaldine sulphate and metomidate. Aquaculture 1991; 96: 69-86.

[34] Knoph MB. Effects of metomidate anaesthesia or transfer to pure sea water on plasma parameters in ammonia-exposed Atlantic salmon (Salmo salar) in sea water. Fish Physiol Biochem 1995; 14(2): 103-9.

[35] Massee KC, Rust MB, Hardy RW, Stickney RR. The effectiveness of tricaine, quinaldine sulfate and metomidate as anaesthetic for larval fish. Aquaculture 1995; 134: 351-9.

[36] Soivio A, Nyholm K, Huhti M. Effects of anaesthesia with MS222, neutralized MS222 and benzocaine on blood constituents of rainbow trout Salmo gairdneri. J Fish Biol 1977; 10: 91-101.

[37] Strange R, Schreck CB, Ewing RD. Cortisol concentration in confined juvenile chinook salmon (Onchorhyncus tshawytscha). Trans Am Fish Soc 1978; 107: 812-9.

[38] Iwama GK, McGeer JC, Pawluk MP. The effects of five anaesthetics on acid base balance, hematocrit, blood gases, cortisol and adrenaline in rainbow trout. Can J Zool 1989; 67: 2065-73.

[39] Mattson NS., Ripple TH. Metomidate a better anesthetic for cod (Gadus morhua) in comparison with benzocaine, MS-222, chlorobutanol and phenoxyethanol. Aquaculture 1989; 134: 351-9.

[40] Mylonas CC, Cardinaletti G, Sigelaki I, Polzonetti-Magni A. Comparative efficacy of clove oil and 2-phenoxyethanol as anesthetic in the aquaculture of European sea bass (Dicentrarchus labrax) and gilthead sea bream (Sparus aurata) at different temperature. Aquaculture 2005; 246: 467-81.

[41] Endo T, Ogihima K, Tanaka H, Oshima S. Study on the anesthetic effect of eugenol in some freshwater fishes. Bull Jpn Soc Sci Fish 1972; 38: 761-7.

[42] Zengh G, Kenney PM, Lam LKT, Ogihima K, Tanaka H, Oshima S. Sesquiterpenes from clove oil, Eugenia caryophillata as potential anticarcinogenic. Agents. J Nat Prod 1992; 55: 999-1003.

[43] Iversen M, Finstad B, McKinley RS, Eliassen RA. The efficacy of metomidate, clove oil, Aqui- $S^{\mathrm{TM}}$ and Benzoak ${ }^{\circledR}$ as anaesthetic in Atlantic salmon (Salmo salar L.) smolts, and their potential stressreducing capacity. Aquaculture 2003; 221: 535-48.

[44] Moore FD. Endocrine changes after anaesthesia, surgery and unanesthetized trauma in man. Rec Progr Horm Res 1957; 13: 51182.

[45] Hedener P, Rerup C. Adrenocortical activity following corticotrophin injection at low adrenal ascorbate levels. Acta Endocrinol 1962; 41: 219-26.

[46] Pickering AD, Ed. Stress in fish. London: Academic Press 1981.

[47] Ortuno J, Esteban MA, Meseguer J. Effects of four anaesthetics on the innate immune response of gilthead sea bream (Sparus aurata L.). Fish Shellfish Immunol 2002; 12: 49-59. 
[48] Robertson L, Thomas P, Arnold CR. Plasma cortisol and secondary stress responses of cultured red drum (Sciaenops ocellatus) to several transportation procedures. Aquaculture 1988; 68: 115-30.

[49] Barton BA, Barton RE. Plasma cortisol stress in fingerling rainbow trout Salmo gairdneri Richardson to various transport condition anaesthesia and cold shock. J Fish Biol 1982; 20: 39-51.

[50] Tort L, Puigcerver M, Crespo S, Padros F. Cortisol stress and haematological response in sea bream and trout subjected to the anaesthetics clove oil and 2-phenoxyethanol. Aquacult Res 2002; 33: 907-10.

[51] Small BC. Anesthetic efficacy of metomidate and comparison of plasma cortisol response to tricaine methanesulfonate, quinaldine and clove oil anaesthetised channel catfish Ictalurus punctatus. Aquaculture 2003; 218: 177-85.

[52] Wedemeyer G. The role of stress in disease resistance in fishes. Am Fish Soc Spec Publ 1970; 5: 30.

[53] Reinitz GL, Rix J. Effect of tricaine methanesulphonate (MS222) on haematocrit values in rainbow trout (Salmo gairdneri). Comp Biochem Physiol C 1977; 56: 863-72.

[54] Houston AH, Czerwinski CL, Woods RJ. Cardiovascularrespiratory activity during recovery from anaesthesia and surgery in brook trout (Salvelinus fontinalis) and carp (Cyprinus carpio). J Fish Res Board Can 1973; 30: 1705-12.

[55] Smith G, Hatting J. Anaesthetic potency of MS222 in three freshwater fish species. Comp Biochem Physiol C 1979; 62: 23741.

[56] Sladky KK, Swanson CR, Stoskopf MK, Loomis MR, Lewbart GA. Comparative efficacy of tricaine methanesulfonate and clove oil for use as anesthetics in red pacu (Piaractus brachypomusi). Am J Vet Res 2001; 62(3): 337-42.

[57] Fromm PO, Richards BD, Humter RC. Effects of some insecticides and MS222 on isolated perfused gills of trout. Prog Fish-Cult 1971; 33: $138-40$.

[58] Holeton GF, Randall DJ. The effects of hypoxia upon the parietal pressure of gases in the blood and water afferent and efferent to the gill of rainbow trout. J Exp Biol 1967; 46: 317-27.

[59] Garey WF, Rahn H. Normal arterial gas tension and $\mathrm{pH}$ and the breathing frequency of the electric eel. Resp Physiol 1970; 9: 14150 .

[60] Barton BA, Peter RE. Plasma cortisol stress response in fingerling rainbow trout, Salmo gairdneri Richardson, to various transport conditions, anaesthesia and cold-shock. J Fish Biol 1982; 20: 3951.

[61] Houston AH, Madden JA, Woods RJ, Miles HM. Some physiological effects of handling and tricaine methanesulphonate anaesthetisation upon the brook trout (Salvelinus fontinalis). J Fish Res Board Can 1971; 28: 625-33.

[62] Duthie GG, Tort L. Effects of dorsal aortic cannulation on the respiration and haematology of Mediterranean living Scyliorhinus canicula. L Comp Biochem Physiol A 1985; 81: 879-83.

[63] Crowley GJ, Berinati DJ. Effect of MS222 on blood sugar and liver glycogen in rainbow trout. Trans Am Fish Soc 1972; 1: 125-8.

[64] Barton BA, Peter RE, Paulencu CR, Loomis MR. Plasma cortisol levels of fingerling rainbow trout, (Salmo gairdneri) at rest and subjected to handling, confinement, transport and stocking. Can J Fish Aquat Sci 1980; 37: 805-11.

[65] Davis LE, Schreck CB. The energetic response to handling stress in juvenile coho salmon. Trans Am Fish Soc 1997; 126: 248-58.

[66] Sharpe CS, Thompson DA, Blankenship HL, Schreck CB. Effects of routine handling and tagging procedures on physiological stress responses in juvenile Chinook salmon. Prog Fish Culturist 1998; 60: $81-7$

[67] Pickering AD. Stress response in farmed fish. In: Black KD, Pickering TG, Eds. Biology of Farmed Fish. Sheffield: Sheffield Academic Press 1998; pp. 222-255.

[68] Arends RJ, Mancera JM, Munoz JL, Bonga SEW, Flik G. The stress response of gilthead sea bream (Sparus aurata L.) to air exposure and confinement. J Endocrinol 1999; 163: 149-57.

[69] FAWC (Farmed Animal Welfare Council). Report on Welfare of Farmed Fish. Surbiton, Surrey 1996.

[70] Scottish Executive. A Strategic Framework for Scottish Aquaculture; Edinburgh, http://www.scotland.gov.uk/library5/ environment/sfsa-00.asp

[71] Olsen YA, Einarsdottir IE, Nilssen KJ. Metomidate anaesthesia in Atlantic salmon Salmo salar, prevents plasma cortisol increase during stress. Aquaculture 1995; 134: 155-68.

[72] Morales AE, Cardenete G, Abellàn E, Garcìa-Rejon L. Stressrelated physiological responses to handling in common dentex (Dentex dentex Linnaeus, 1758). Aquacult Res 2005; 36: 33-40.

[73] Rotland J, Balm PHM, Perez-Sànchez J, Wendelaar Bonga S, Tort L. Pituitary and interregnal function in gilthead sea bream (Sparus aurata L., Teleostei) after handling and confinement stress. Gen Comp Endocrinol 2002; 121: 333-42.

[74] Maricchiolo G, Garaffo M, Micale V, Muglia U, Genovese L. The use of MS222 during routine aquaculture procedures anol biochemical response of blackspot sea bream Pagellus bogaraveo. European Aquaculture Society: EAS Special Publ 32 2002; pp. 327-328. 